\section{Time to leave rigid traditions in Type 1 diabetes research}

\author{
"In spite of modern treatment and progress with devices ... \\ Type 1 diabetes is a severe, life-threatening disease, which should \\ be cured and prevented. Let us hope the time has come when \\ diabetologists leave their fixed paradigms and rigid opinions, \\ and open up for new efforts in selected groups."
}

First draft submitted: 1 May 2017; Accepted for publication: 18 May 2017; Published online: 27 June 2017

After the finding of insulitis [1] and in the discoveries of auto antibodies [2,3] and connection of HLA to certain type of insulindependent diabetes [4], it became evident that diabetes could be divided into two main types. Type 1 diabetes (T1D) seemed to have an autoimmune process as part of its pathogenesis. By the end of that decade, the first immune intervention (plasmapheresis) was tried to preserve residual $\beta$-cell function in newly diagnosed patients [5] and a few years later, the efficacy of cyclosporin was regarded as a proof of concept [6]. Already in the 1980s, it was proposed that the CD3receptor should be blocked and there was a great interest in T-regulatory cells, which were called suppressor cells at that time. The models of autoimmune diabetes in experimental animals gave us an ocean of methods which stop the disease process and have now passed several hundred different methods. However, not a single method has worked well enough to treat T1D in humans and we seem to have reached a dead-end. In ClinicalTrials.gov, we can find an enormous number of trials. Searching with the keywords 'T1D+ immune intervention' gives 1438 studies, 'T1D+ C-peptide' gives 583 studies, 'T1D+ immune intervention+ children' gives 528 studies etc., There are at least 40 registered ongoing immune intervention trials in T1D but still there is no real optimism. Few, if any of these studies were presented or even mentioned at the Immunology Diabetes Society meeting in San Francisco, Jan 2017, and there was a little discussion on what explains the lack of progress. Have we all misunderstood? Is T1D not an autoimmune disease? Some researchers point to findings that suggest the insulitis found in T1D is not unique, but also found in T2D, while others argue against this as there are major differences in the picture. Others draw attention to the similarities between T1D and T2D, and claim that factors usually associated with T2D, may also be involved in the pathogenesis of T1D [7].

\section{How have others worked?}

There are areas in medicine with greater success. Rheumatoid arthritis has modern effective therapies since more than a decade. It may be easier to follow the clinical benefit of such treatment than in T1D. Cancer stirs the emotions of people and resources for research have grown immensely. This has facilitated research, but is not the only explanation to progress. In cancer, the threat of death has allowed physicians and researchers to try more unconventional approaches, and both patients, their family and clinicians have been more motivated. When a single cytostatic did not cure the patients, and next cytostatic did not work either, the conclusion was not to discard those drugs, but to combine them $[8,9]$. We (I worked in pediatric oncology for decades) discussed where in the cell cycle the different cytostatics worked, tried to combine and create regimens. Adverse events of the different drugs were taken into account to adjust doses of cytostatics with similar side

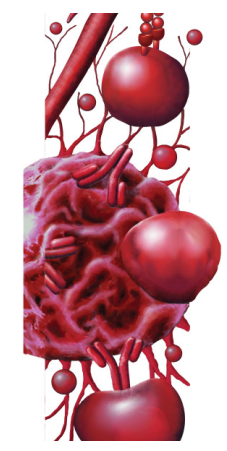

Johnny Ludvigsson Division of Pediatrics, Department of Clinical \& Experimental Medicine, Linköping University, Sweden johnny.ludvigsson@liu.se

Future $\because \%$ Medicine part of 
effects. Some patients went into long remissions, and a few were even cured. Instead of discarding a regimen with effect only in a minority of the patients, we analyzed the criteria of those who seemed to respond. In Acute Lymphatic Leukemia, it was found early that children aged $2-10$ years old responded best, especially girls. Not children under 2 years of age, nor children above 10 years of age, not those with very high-number of leucocytes, not those with splenomegaly or hepatomegaly, or those with infiltration in CNS or testicles etc. Should we then give up those patients? No, instead different regimens were tried in those groups, trial after trial. In 10-20 years, the prognosis had improved dramatically. It has been known for a long time that acute leukemia is not one disease, but it became clear that not even Acute Lymphatic Leukemia can be treated in the same way, but has to be treated differently in different subgroups of patients.

\section{Lack of motivation to preserve $\beta$-cell function in T1D}

Although, T1D can be treated with insulin, some sufferers will die rather young, and some will have severe complications, but we cannot predict who they will be. Patients are not interested in partaking in trials to preserve $\beta$-cell function when their physicians or diabetes team comfort them by informing them, a false message, that with the existing treatment, they will be able to lead 'a normal life'. Clinicians and diabetes teams are too occupied in helping their patients to obtain a good HbAlc, that they are not willing to spend time on intervention trials. Medical Product Agencies have been fixed to the idea that residual $\beta$-cell function is of limited or no value unless the insulin requirement decreases, and only in recent years have accepted that $\beta$-cell function is important.

\section{T1D is a heterogenous disease}

The paradigm for decades has been that T1D is one disease, and that's it! Thus, males and females must be treated exactly in the same way, and those who get the disease at the age of 4 years have the same disease as those who get the disease at the age of 45 , and should therefore be treated in the same way. When the treatment does not work, then it is something wrong with the treatment, not with the design of the trial. In accordance with this paradigm, one can still notice that ongoing trials registered in ClinicalTrials.gov include patients between 8 and 55, 4 and 60, 6 and 45, 12 and 35 years etc. As if the patients in these wide age ranges should have the same disease process and the same natural course. One can be afraid that the conclusions from failing trials will be that the drug just did not work!

\section{One drug at a time or a combination?}

The drug? Yes, most studies to preserve $\beta$-cell function in T1D studies are dealing with one single drug or approach, again and again. When enough studies have been performed to show that Anti-CD3 alone in different doses does not sufficiently preserve $\beta$-cell function in all ages and populations over the world, no drug company seems to be willing to continue this research. Some patients did respond rather well for example, $<18$ years, with short duration of disease, especially those with higher C-peptide. The natural conclusion would be to include those in whom the treatment really seems to work in the next trial. For others who do not respond as favorably, we need to combine treatment with something else. Perhaps another few patients then will respond? However, these stepwise efforts are uncommon in T1D. We have seen some efficacy, usually transient, of a number of regimens, and a number of drugs, but none has been accepted.

\section{What can be done?}

\section{Select the right patients}

T1D is heterogenous. That has been known by clinicians for decades $[10,11]$. Some patients have a more stable disease, a slower decline of residual $\beta$-cell function. There is a difference between very young children, school children, teenagers, adults, the elderly, and there is a difference between females and males. Some patients react with autoantibodies to certain antigens, others to other autoantigens. As patients have different genetic backgrounds, the cell-mediated immune respond is different and the cytokine concentrations are different. We need to better analyze who responds to a treatment and who do not respond, and thus, improve inclusion criteria.

\section{Combine drugs}

There are several drugs that seem to have some efficacy, for example, AntiCD3, TNF-alfa inhibitors, ATG, Alefacept, Rituximab. There is a high probability that autoantigen treatment with GAD-alum, but probably also with insulin and/or proinsulin peptides, has efficacy to preserve $\beta$-cell function [12]. There are also indications that some factors/mechanisms either protect the $\beta$ cells or influence the immune system in a positive way, such as vitamin $\mathrm{D}$, omega-3-fatty acids, nicotinamide, probiotics, and perhaps it is of value for some patients to avoid gluten during a certain period [13]. Perhaps all the studies on GLP-1 (just now at least five ongoing trials using GLP-1 agonists or DPP4-inhibitors to preserve $\beta$-cell function) will show whether GLP-1 can improve $\beta$ cell survival or proliferation. 
But then, researchers and funding agents have to dare unconventional combination therapies. My applications have been in vain, and others may have similar problems. In ClinicalTrials.gov I found only one such unconventional combination therapy trial (Riccordi and Skyler as senior responsible ClinicalTrials.gov Identifier: NCT02586831), and this trial has been waiting to start for quite some time.

\section{Realistic expectations}

In spite of modern treatment and progress with devices such as glucose sensors, pumps etc. T1D is a severe, life-threatening disease, which should be cured and prevented. Let us hope the time has come when diabetologists leave their fixed paradigms and rigid opinions, and open up for new efforts in selected groups.

\section{References}

1 Gepts W, Lecompte PM. The pancreatic islets in diabetes. Am. J. Med. 70 (1), 105-115 (1981).

2 Bottazzo GF, Florin-Christensen A, Doniach D. Isletcell antibodies in diabetes mellitus with autoimmune polyendocrine deficiencies. Lancet 2(7892), 1279-1283 (1974).

3 MacCuish AC, Irvine WJ, Barnes EW, Duncan LJ. Antibodies to pancreatic islet cells in insulin-dependent diabetics with coexistent autoimmune disease. Lancet 2(7896), 1529-1531 (1974).

4 Svejgaard A, Platz P, Ryder LP, Nielsen LS, Thomsen M. HL-A and disease associations--a survey. Transplant. Rev. 22, 3-43 (1975).

5 Ludvigsson J, Heding L, Liedén G, Marner B, Lernmark A. Plasmapheresis in the initial treatment of insulin-dependent diabetes mellitus in children. Br. Med. J. (Clin. Res. Ed.) 286(6360), 176-178 (1983).

6 Stiller CR, Laupacis A, Dupre J et al . Cyclosporine for treatment of early Type I diabetes: preliminary results. $N$. Engl. J. Med. 308(20), 1226-1227 (1983).

7 Ludvigsson J. Why diabetes incidence increases--a unifying theory. Ann. N Y Acad. Sci. 1079, 374-382 (2006).
It is much better to prevent $10 \%$ than $0 \%$, and much better with $30 \%$ preservation of $\beta$-cell function during 5 years in $20 \%$ of patients, even if the majority of these were just males, or just females, than no preservation at all. Such steps will be the beginning of a cure for some patients.

\section{Financial \& competing interests disclosure}

The author has no relevant affiliations or financial involvement with any organization or entity with a financial interest in or financial conflict with the subject matter or materials discussed in the manuscript. This includes employment, consultancies, honoraria, stock ownership or options, expert testimony, grants or patents received or pending, or royalties.

No writing assistance was utilized in the production of this manuscript.
M. Effective combination treatment of advanced acute lymphocytic leukemia with cytosine arabinoside (NSC63878) and L-asparaginase (NSC-109229). Cancer Chemother. Rep. 56(3), 363-368 (1972).

9 Borella L, Green AA, Aur RJ, Simone JV, Pinkel D. Clinical and immunological recovery of children with acute lymphocytic leukemia admitted to "total therapy" studies. Recent Results Cancer Res. 43, 145-150 (1973).

10 Ludvigsson J, Samuelsson U, Beauforts C et al. HLA-DR 3 is associated with a more slowly progressive form of Type 1 (insulin-dependent) diabetes. Diabetologia 29(4), 207-210 (1986).

11 Ludvigsson J, Afoke AO. Seasonality of Type 1 (insulindependent) diabetes mellitus: values of C-peptide, insulin antibodies and haemoglobin A1c show evidence of a more rapid loss of insulin secretion in epidemic patients. Diabetologia 32(2), 84-91 (1989).

12 Beam CA, MacCallum C, Herold KC et al. GAD vaccine reduces insulin loss in recently diagnosed Type 1 diabetes: findings from a Bayesian meta-analysis. Type 1 Diabetes TrialNet Study Group. Diabetologia 60 (1), 43-49 (2017).

13 Rewers M, Ludvigsson J. Environmental risk factors for Type 1 diabetes. Lancet 387(10035), 2340-2348 (2016). 
